Docent dr Milorad Vidović, dipl. inž. profesor dr Momčilo Miljuš, dipl. inž. Saobraćajni fakultet,
Beograd

\section{LOKACIJSKI PROBLEMI - ZNAČAJ, VRSTE I NAČINI REŠAVANJA}

UDC: $330.341 .46: 711: 355.41$

Rezime:

Lokacijski problemi, u širem smislu, odnose se na određivanje pozicije jednog ili grupe objekata u prostoru određene dimenzionalnosti. U užem smislu, posebno u logistici, ovi problemi odnose se na lociranje resursa, skladišnih objekata, terminala, pretovarnih mesta, ... i sl., pa je po pravilu reč o zadacima lociranja tačke u dvodimenzionom prostoru. To je logično kada se ima u vidu da se dimenzije, npr. skladišnog objekta, mogu zanemariti u odnosu na teritoriju na kojoj se objekat locira. Teorija lokacije bavi se formulacijom i rešavanjem lokacijskih problema, pri čemu je te probleme moguće klasifikovati u odnosu na: broj objekata koji se lociraju, karakter raspoloživih lokacija, kriterijume koji se koriste pri izboru lokacije, karakter zadataka koji se rešavaju, tip ciljne funkcije, pristup i metode koje se koriste pri izboru lokacije. U ovom radu prikazane su osnovne postavke lokacijske teorije, formulisani osnovni tipovi problema i definisani mogući pristupi za njihovo rešavanje, uključujući $i$ neke od tipično vojnih primena.

Ključne reči: lokacijska analiza, teorija lokacije.

\title{
LOCATION PROBLEMS - IMPORTANCE, TYPES AND SOLVING METHODS
}

Summary:

In their wider sense, location problems are related to locating one ore more objects in the area of certain dimensionality. In narrower sense, particularly in logistics, these problems are related to locating resources, warehouses, terminals,... Hence, these are problems of locating points in the two dimensional space. This sounds logical since for example, warehouse dimensions, may be neglected in comparison with the area where the object is located. The location theory deals with formulation and solving location problems. Such problems may be classified with respect to: number of objects, location type (discretecontinuous), criterions, tasks realized by the system, objective function types applied solution methods, etc. This paper is organized to present the basic concepts in the location theory, defining fundamental problems and proposing general approaches to their solution. Some of typically military applications are also discussed.

Key words: location analysis, location theory.

\section{Uvod}

Lociranje proizvodnog pogona, skladišta, distributivnog centra, terminala, ili nekog drugog čvorišta u logističkom lancu, kao i lociranje protivpožarne stanice, stanice hitne pomoći, deponije otpadnog materijala i sličnih resursa, predstavlja kompleksan zadatak strateškog planiranja. Realizacija ovih zadataka povezana je, sa jedne strane, sa visokim investicionim ulaganjima, a sa druge i sa značajnim rizicima, kako onim finansijskim, tako i ekološkim i onim koji rezultiraju iz izostalog kvaliteta realizacije zahteva koji su inicirali lociranje nekog resursa. 
Nema nikakve sumnje da je upravo svest o značaju lokacijskih problema inicirala veliki broj istraživanja, pa je kao rezultat toga u svetskoj literaturi moguće pronaci više od 3000 publikovanih radova iz ove oblasti. Teoretičari i praktičari iz oblasti operacionih istraživanja razvili su veliki broj modela i nude ogroman broj pristupa rešavanju problema iz tog domena. Sa jedne strane, to svakako predstavlja prednost, ali mnoštvo informacija o tipovima problema i načinima njihovog rešavanja predstavlja i objektivnu prepreku svakom pokušaju obuhvatnijeg pristupa lokacijskim problemima, odnosno izlaganju lokacijske teorije. Pri tome, lokacijski problemi odnose se na određivanje mesta ili pozicije nekog objekta ili grupe objekata u prostoru određene dimenzionalnosti, a teorija lokacije bavi se formulacijom i rešavanjem tih problema. Kada se govori o ,dimenzionalnosti“", reč je u stvari o prisustvu različitih mogućih kombinacija objekta koji je potrebno locirati i prostora $\mathrm{u}$ kojem se taj objekat locira. Naime, u svom širem značenju lokacijski problemi - ako se posmatraju samo tipične kombinacije, mogu se odnositi na lociranje 3D tela - kvadra u 3D prostoru (tovarenje vozila, kontejnera, ...), na lociranje $2 \mathrm{D}$ površine pravougaonika u ravni (sečenje ploča, problemi prostornog raspoređivanja elemenata sistema - layout), lociranje 1D objekta - linije u 1D prostoru (sečenje šipki, lociranje komisione zone u regalskom prolazu), odnosno na lociranje 0D objekta - tačke, u 2D prostor, ravan, ili pak u 1D prostor - na liniju. Međutim, u užem smislu i uobičajenom značenju teorija lokacije razmatra probleme lociranja tačke $u$ dvodimenzionalnom prostoru $(0 D \& 2 D)$, s ob- zirom na to da su dimenzije sistema koji je potrebno locirati (objekta - kompleksa) zanemarljive $\mathrm{u}$ odnosu na prostor $\mathrm{u}$ kojem se lokacija bira (teritorija grada, regija, područje države, region koji obuhvata više država,...).

Lokacijske probleme moguće je klasifikovati u odnosu na planski horizont (statički i dinamički problemi), u odnosu na broj objekata koji se lociraju (lociranje jednog objekta ili više objekata), karakter raspoloživih lokacija (diskretan prostor: mreža, ili konačni broj pozicija), prema kriterijumu koji se koristi pri izboru lokacije (medijana - težište, centar, anti-centar), prema karakteru zadatka koji se rešava (lokacijski, alokacijski, lokacijsko-alokacijski), u odnosu na tip ciljne funkcije (jednokriterijumska, višekriterijumska), kao i u odnosu na pristup i metode koje se koriste pri izboru lokacije (intuitivni pristup, egzaktni optimizacioni model, simulacija, heuristički modeli, ekspertni sistem). Iako i ova klasifikacija dovoljno govori o kompleksnosti problematike razmatrane u ovoj oblasti, treba naglasiti da time nisu iscrpljeni svi aspekti lokacijske teorije, niti obuhvaćene sve klase problema.

Ovim radom obuhvaćeni su samo neki od tipičnih problema i načini za njihovo rešavanje, i upućuje se na veoma obimnu literaturu iz ove oblasti, čiji se iscrpan prikaz može pronaći na adresi koja u ovom trenutku ima 3400 naslova: http://www. ent.ohiou.edu/ thale/thlocation.html.

\section{Razvoj lokacijske teorije}

Razvoj lokacijske teorije u literaturi uglavnom se vezuje za agronomiju i geo- 
grafiju, pa se kao začetnici ove oblasti najčešće navode nemački agroekonomista Johann Heinrich von Thünen (1875), odnosno Alfred Weber (1929) koji razmatra industrijsku proizvodnju. Tako se Thünenu pripisuje prva od lokacijskih teorija, bazirana na razmatranju troškova i rastojanja, gde se za pogone poljoprivredne proizvodnje kaže da se u odnosu na tržište prodaje moraju locirati tako da minimiziraju transportne troškove. Weber prepoznaje značaj sirovina u odvijanju proizvodnih procesa i u tome uticaj lokacije. Tako, Weber uočava da su količine sirovina u industriji čelika veće od količine gotovih proizvoda, pa zaključuje da je radi minimizacije transportnih troškova proizvodne pogone potrebno približiti izvorima sirovina. Međutim, on takođe uočava i prisustvo proizvoda kod kojih su sirovine prisutne praktično svuda (npr. vazduh i voda), pa zaključuje da je u tom slučaju, radi minimizacije transportnih troškova, proizvodne pogone potrebno locirati što bliže tržištu, to jest potrošačima.

Ipak, posmatrano sa aspekta matematičke formulacije, smatra se da je čuveni Ferma (Fermat Pierre de 1601-1665) početkom XVII veka započeo razmatranje lokacijskih problema ukazujući na sledeći problem: „Za zadate tri tačke u ravni pronaći četvrtu, tako da zbir rastojanja između četvrte tačke i zadate tri, bude minimalan".

Idući još dalje u prošlost, Dickman (1995) postavku lokacijskog problema nalazi u Bibliji, u Starom zavetu, u Petoj knjizi Mojsijevoj (Gl. 19, 1-10)' : „1) Kad Gospod

Sveto pismo Staroga i Novoga zavjeta, u prevodu Đ. Daničića (Stari zavjet) i Vuka S. Karadžića (Novi zavjet), Izdanje britanskog i inostranog biblijskog društva 1985.
Bog tvoj potre narode kojih zemlju daje tebi Gospod Bog tvoj, i kad ih naslijediš i nastaniš se po gradovima njihovijem i po kućama njihovijem, 2) Odvoj tri grada usred zemlje svoje koju ti daje Gospod Bog tvoj da je naslijediš, 3) Načini put i razdijeli na troje krajeve zemlje svoje, koju ti da Gospod Bog tvoj u našljedstvo, pa neki bježi onamo svaki krvnik, ..."

Rešenje navedenog lokacijskog problema, ovde citiranog samo delimično, navodi se u Knjizi Isusa Navina (Gl. 20, $7)^{2}$, kao ispunjenje Božje zapovesti: „I odjeliše Kedes u Galileji u gori Neftalimovoj, i Sihem u gori Jefremovoj i Kirijat-Arvu, to je Hevron u gori Judinoj“".

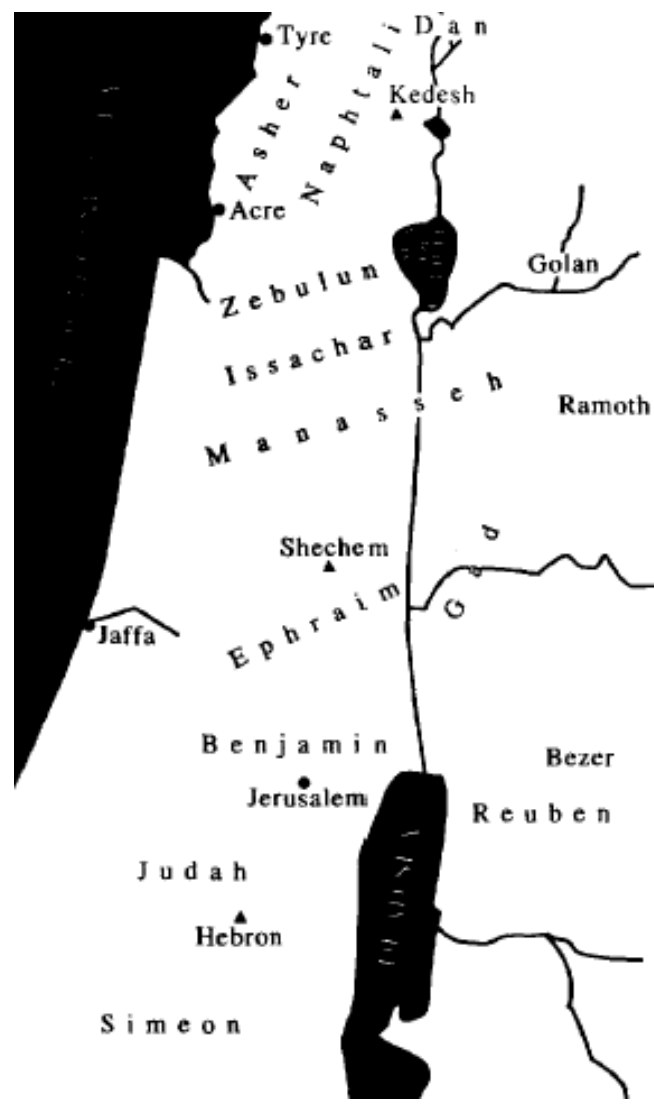

Sl. 1 - Biblijski lokacijski problem 
Lokacijska teorija ponovo ulazi u žižu interesovanja sa radom S. L. Hakimi (1964), koji razmatra lociranje čvorova komunikacione mreže i policijskih stanica na mreži autoputeva. U tom radu Hakimi razmatra mnogo opštiji problem lociranja jednog ili više objekata na mreži, sa ciljem minimizacije ukupnog rastojanja između korisnika i njima najbližeg objekta, ili sa ciljem minimizacije maksimalnog rastojanja od korisnika do objekta na koji su oslonjeni.

Od sredine šezdesetih godina prošlog veka lokacijska teorija počinje sve više da se razvija, matematski se formulišu različiti tipovi lokacijskih problema i prezentiraju se različiti algoritmi za njihovo rešavanje.

\section{Osnovni tipovi lokacijskih problema}

Respektujući višedimenzionalnost i veliki broj kriterijuma koji bi mogli biti korišćeni pri kategorizaciji lokacijskih problema, za potrebe ovog rada izdvojeni su samo oni najznačajniji, i na osnovu toga učinjen je pokušaj određenog struktuiranja tipičnih grupa zadataka iz domena lokacijske analize. Naravno, prikazani način struktuiranja lokacijskih problema nije i jedini mogući, niti sveobuhvatan, a neke aspekte klasifikacije lokacijskih problema detaljnije su razradili $\mathrm{H}$. W. Hamacher, Nickel (1998), koji su, takođe, predložili i jednu od mogućih klasifikacionih šema.

\section{Statički-dinamički lokacijski problemi}

Pod statičkim problemima podrazumevaju se formulacije kojima se ne obu- hvata dinamika promene relevantnih parametara za izbor lokacije, pa tako ni eventualna faznost u uvođenju rešenja. Statički problemi najčešće su i deterministički, a treba naglasiti da je najveći broj modela koji su u primeni upravo ovog tipa - statički. Sa druge strane, dinamičke formulacije lokacijskih problema, s obzirom na činjenicu da su lokacijski problemi u svojoj suštini strateškog karaktera dugoročni, pokušavaju da u analizu uključe i određen stepen neizvesnosti koji je moguće očekivati u perspektivi. Otuda je ideja ove klase lokacijskih modela da u planiranje uključe dinamiku ponašanja zahteva u budućnosti.

\section{Kontinualni - diskretni (mrežni) lokacijski problemi}

U slučaju kontinualnih problema izabrana lokacija može biti bilo gde u oblasti dopuštenog prostora, a u slučaju diskretnih lokacijskih problema bira se jedna ili više od skupa potencijalno raspoloživih lokacija. Dakle, u slučaju kontinualnih problema broj raspoloživih lokacija je beskonačan, a u diskretnim problemima konačan i unapred poznat (slika 2).

\section{Lociranje jednog ili više objekata}

Razlika u broju objekata koje je potrebno locirati direktno determiniše način rešavanja odnosnog lokacijskog problema.

\section{Postojanje - nepostojanje kapacitivnih ograničenja}

Odnosi se na postojanje ograničenja u pogledu maksimalnog kapaciteta objekta 


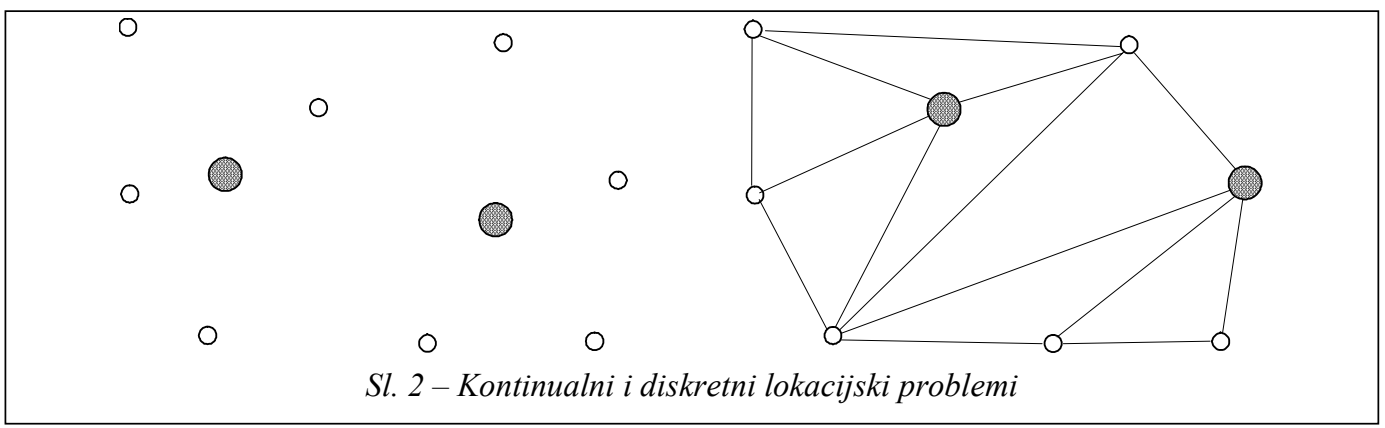

na određenoj lokaciji, ili na ograničenja kapaciteta transportnih sredstava koja realizuju tokove, što je posebno značajno za kombinovane lokacijske i ruting-probleme.

\section{Lokacijski, alokacijski i lokacijsko- -alokacijski problemi}

U suštini, problem lociranja resursa sadrži tri grupe potproblema: određivanje broja objekata koji se lociraju, njihove pozicije na mreži i povezivanje korisnika sa lokacijama. Lokacijski problemi („,̌cisti“) prisutni su prevashodno u slučaju lociranja jednog objekta, kada se svi „korisnici“ oslanjaju na tu jednu izabranu lokaciju. Po pravilu, u slučaju da je broj objekata koji se lociraju veći od 1, potrebno je i alocirati korisnike, tj. svakog korisnika „dodeliti“" nekom od objekata. Lokacijski problem (bez alociranja korisnika) prisutan je i kod preliminarne analize skupa potencijalno raspoloživih lokacija, kada se problem obično rešava primenom kvalitativne analize.

Alokacijski problemi odnose se na „dodeljivanje“ korisnika skladišnim lokacijama, tj. na način povezivanja korisnika (ili grupe korisnika u zoni) i skladišnih lokacija. Jasno je da alokacija podrazumeva da su poznate lokacije korisni- ka i lokacije skladišta. Alokacija korisnika često se realizuje na bazi najkraćeg puta, ali se optimalna alokacija, za poznate lokacije korisnika i skladišta, kao i za poznate tokove koji se realizuju, i poznate troškove transporta, uspešno utvrđuje rešavanjem transportnog zadatka.

Lokacijsko-alokacijski problemi rešavaju se u slučaju da je potrebno locirati više od jednog skladišnog objekta. Kada je reč o lociranju skladišta i lokacijskim problemima u logistici uopšte, onda je baš ova klasa problema najčešća. Postoji izuzetno veliki broj pristupa za rešavanje ovih problema, kako u kontinualnom, tako i u diskretnom slučaju.

\section{Kvalitativni i kvantitativni pristup rešavanju problema}

U slučaju da se radi o diskretnim lokacijskim problemima, koji podrazumevaju postojanje određenog broja raspoloživih lokacija, izbor konkretne lokacije može se realizovati ili na bazi kvantitativne analize - primenom nekog od modela koji najčešće analiziraju transportne i skladišne troškove, ili na bazi odgovarajuće kvalitativne analize. Kvalitativna analiza može se sprovesti tehnikom „check list“, ali i korišćenjem neke od tehnika višekriterijumske analize. 


\section{Jednoešelonski i multiešelonski problemi}

Multiešelonski problemi uvek podrazumevaju tokove između objekata na pojedinim nivoima, a jednoešelonski sistemi mogu, ali i ne moraju da podrazumevaju interakciju - realizaciju robnih tokova između objekata. Tako višeešelonski skladišni sistemi podrazumevaju, u suštini, postojanje hijerarhijski uređenog sistema skladišta koja su organizovana po nivoima - centralno, regionalna,... Pri tome, skladišta jednog nivoa snabdevaju ona sa sledećeg nižeg.

\section{Problemi lociranja habova}

Primeri hab-mreža mogu se pronaći u sistemima za isporuku ekspres pošiljki, kod avio i drumskih prevoznika, kao i u različitim računarskim i telekomunikacionim mrežama. Modeli lociranja habova razlikuju se od ostalih tipova lokacijskih problema i po tome što se zahtevi definišu kao tokovi između čvorova, a ne kao u slučaju konvencionalnih diskretnih lokacijskih problema. Hab-mreže uključuju tri tipa čvorova: izvore, destinacije i habove, kao i lukove preko kojih se realizu-

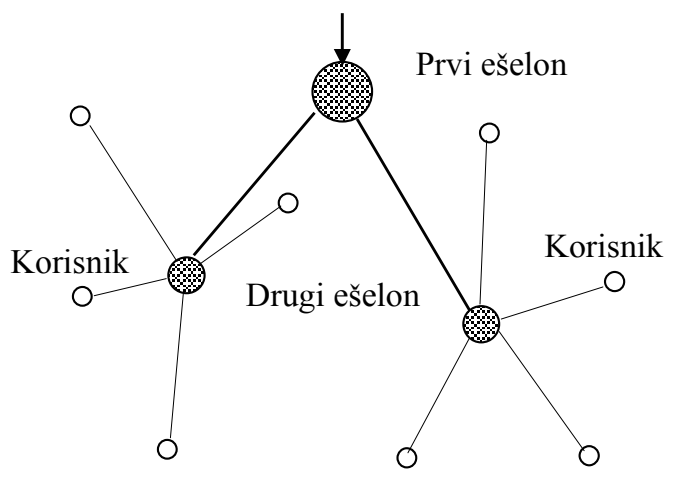

Sl. 3 - Ešelonski lokacijski problem

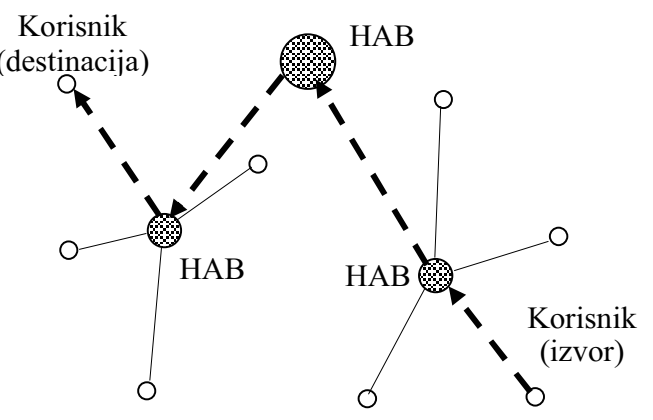

Sl. 4-HAB lokacijski problem

ju transportni tokovi. Mreže ovog tipa obezbeđuju povezivanje izvorišnih i odredišnih čvorova rutiranjem tokova preko habova. Opšti tip hab-lokacijskog problema uključuje lociranje habova i definisanje ruta za transportne tokove između izvorišnih i odredišnih čvorova.

\section{Jednokriterijumski i višekriterijumski problemi}

Širok spektar raspoloživih tehnika operacionih istraživanja i metoda podrške odlučivanju nudi mogućnost traženja optimalnog rešenja u prostoru jednog ili više kriterijuma, pa su s tim povezane i različite formulacije lokacijskih problema.

\section{Problemi medijan, centar $i$ anticentar}

Za razumevanje suštinske razlike između ova tri tipa problema, odnosno tri tipa ciljne funkcije, možda je najjednostavnije iskoristiti primer koji navodi Goetschalckh (2000), definišući ove tri karakteristične tačke na brojnoj osi (slika 5).

Problem medijan ili „minisum“ označava pristup u kojem se ciljna funkcija formira tako da se lociranje objekta realizuje na bazi minimizacije srednjeg 
rastojanja - troškova između objekta koji se locira i korisnika:

$$
\min _{x}\left\{\sum_{j} C_{j}(X)\right\}
$$

Ovaj pristup najčešći je u logistici i primenjuje se pri rešavanju najvećeg broja lokacijskih problema.

Problem centar ili ,minimax“ označava pristup u kojem se ciljna funkcija formira tako da se lociranje skladišta realizuje na bazi minimizacije rastojanja do najudaljenijeg korisnika:

$$
\min _{x}\left\{\max _{j} C_{j}(X)\right\}
$$

Tipičan primer su problemi lociranja stanice hitne pomoći, vatrogasne jedinice, kao i skladišta u nekom servisnom centru.

Anticentar ili „maximin“ označava pristup u kojem se ciljna funkcija formira tako da se lociranje skladišta realizuje na bazi maksimizacije rastojanja do najbližeg korisnika.

$$
\max _{x}\left\{\min _{j} C_{j}(X)\right\}
$$

Tipičan primer su problemi lociranja deponija za otpad, skladišta opasnih roba i slično.

Ukoliko se uz navedene kriterijume klasifikacije uoči da je pri rešavanju problema moguće koristiti i različite algoritme - tehnike (matematičko programiranje, analitičke metode, grafičke metode, hibridne tehnike i heuristike), naznačena višeznačnost, kompleksnost i prisustvo

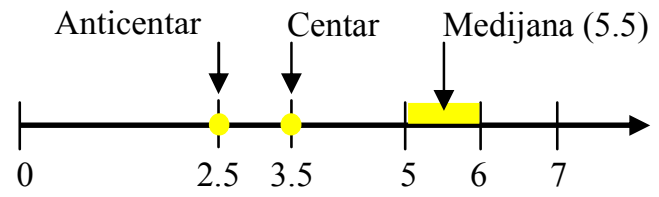

Sl. 5 - Pozicije medijane, centra i anticentra na brojnoj osi sa ,zahtevima“ jednakim brojnim vrednostima u tačkama 0, 5, 6 i 7

različitih klasa lokacijskih problema postaje očigledna.

\section{Formulacija i način rešavanja lokacijskih problema}

\section{Pristupi rešavanju lokacijskih problema}

U principu, tehnike rešavanja lokacijskih problema zasnivaju se, najčešće, na minimizaciji ponderisanih transportnih troškova (vremena, distance) od objekta koji se locira do korisnika, pri čemu se troškovi gradnje objekta na određenoj lokaciji ponekad uključuju u analizu, a ponekad ne.

Generalno gledano, rešavanje lokacijskih problema u principu je povezano sa obimnim i kompleksnim utvrđivanjem i analizama podataka. U praksi, mnogi faktori utiču na izbor lokacije, a ovde su navedeni neki od najznačajnijih, prema Heragu (1997): blizina izvoru sirovina; troškovi i raspoloživost priključaka na električnu mrežu; troškovi, raspoloživost, obučenost i produktivnost radne snage; zakonska regulativa na saveznom, republičkom regionalnom i lokalnom nivou; porezi i takse na saveznom, republičkom regionalnom i lokalnom nivou; osiguranje; troškovi i cena gradnje; politička stabilnost; fluktuacija kursa; uvozno-izvozna regulativa, porezi i takse; transportni sistem; regulativa u oblasti zaštite okoli- 
ne; javni servisi - škole, bolnice, objekti za rekreaciju; ostali servisi; klima; udaljenost korisnika; poslovna klima; faktori vezani za konkurenciju.

Poznavanje samo optimizacionih metoda lokacijske analize najčešće nije dovoljno za određivanje lokacije logističkog sistema, ali primena tih metoda obezbeđuje kvalitetnu podlogu za izbor lokacije, posebno ako se i pomenuti kriterijumi uključe u analizu. Kako definisanje pozicije nekog objekta unutar nekog geografskog područja nije dovoljno za instalaciju tog sistema, u literaturi se problem izbora optimalne lokacije, po pravilu, raščlanjuje u tri faze (Freese, T., 1994):

- makroanaliza (koja ima za cilj određivanje broja i približne lokacije skladišta),

- mikroanaliza (bliže određivanje lokacije - uže područje, deo grada,...),

- precizan izbor lokacije (veoma detaljna analiza sa različitih aspekata, na osnovu koje se donosi odluka).

Za formulisanje i rešavanje lokacijskih problema na raspolaganju je veliki broj različitih pristupa i metoda:

- intuitivni pristup (često se primenjuje, premda se ne može govoriti o unificiranom pristupu. Dolaze do izražaja intuicija, pronicljivost, iskustvo i lična sposobnost, a kao podrška koriste se jednostavni proračuni. Sve ono što veoma teško može biti uključeno u model - subjektivni faktori, izuzeci, ograničenja,... uzima se u obzir kroz grubu analizu, pa su rezultati često zadovoljavajući. Ovaj pristup često se koristi i kao jedna od faza u izboru lokacije, uz primenu neke egzaktnije tehnike);

- simulacioni modeli (s obzirom na to da je reč o univerzalnoj tehnici koja podrazumeva sprovođenje eksperimenta na modelu, simulacija se koristi i kao alat za rešavanje lokacijskih problema. Pristup se svodi na simulaciju različitih „scenarija“, tj. različitih konfiguracija sistema i dozvoljava respektovanje stohastičnosti, kao i drugih specifičnosti ili detalja. Postoje i gotovi softverski paketi LREPS, LOCATE, LSD, ...);

- heuristike (kao tehnike za utvrđivanje zadovoljavajućih rešenja obezbeđuju rešavanje kompleksnih lokacijskih modela koji uključuju veći broj parametara, a jedine su tehnike koje obezbeđuju rešavanje problema većih dimenzija - lociranje više objekata u slučaju kada je prisutan veliki broj potencijalnih lokacija);

- optimizacioni modeli (garantuju najbolje rešenje $u$ odnosu na postavljenu funkciju cilja, a bazirani su na optimizaciji odnosa transportnih i troškova skladištenja. Postoji izuzetno veliki broj različitih modela: gravitacioni model, p-median problem, ... koji mogu biti rešavani kao LP, mrežni problemi, problemi dinamičkog programiranja,...);

- ekspertni sistemi (kompjuterski programi bazirani na veštačkoj inteligenciji koji, koristeći bazu ekspertskog znanja, rešavaju probleme slično ekspertskom timu. Popularnost ovih programa raste, mada se često ekspertskim sistemom nazivaju i programi koji nisu bazirani na konceptu veštačke inteligencije);

- sistemi za podršku odlučivanju (kombinacija baze podataka sa različitim alatima i tehnikama modeliranja, proračuna i evaluacije jeste ono što se danas naziva sistemom za podršku odlučivanju. Reč je o programima koji sadrže odgovarajuće baze podataka, ali i neke od optimizacionih metoda ili heurističkih tehnika). 


\section{Metode za rešavanje lokacijskih problema}

Imajući u vidu prethodno izložene opšte principe rešavanja lokacijskih problema očigledno je da je, generalno uzevši, na raspolaganju širok spektar mogućih metoda pristupa, optimizacionih i heurističkih tehnika. Međutim, moguće je izdvojiti i one metode koje su najčešće u primeni, koje imaju fundamentalni značaj u ovoj oblasti, i koje najbolje ilustruju samu ideju formulacije i pristupa rešavanju lokacijskih problema. Tako, na primer, S. H. Owen i Daskin M. (1998) u kategoriji diskretnih modela razmatraju „medijan problem“, „problem pokrivanja“3, ,problem centra“", kao i neke modifikacije ovih pristupa za slučajeve rešavanja stohastičkih, odnosno uopšte dinamičkih problema. Takođe, u kategoriji kontinualnih modela, u literaturi se često prezentira gravitacioni model za izbor lokacije jednog objekta.

\section{Gravitacioni model za odredivanje lokacije jednog objekta u kontinualnom slučaju}

Ideja algoritma je u izboru lokacije objekta na bazi nalaženja težišta, koje se utvrđuje na bazi minimalnog transportnog rada (proizvod ukupnih zahteva korisnika i rastojanja do objekta koji se locira). Pri tome, lokacija objekta može biti bilo gde u prostoru na kojem se nalaze korisnici.

Jedan od pristupa koji pojednostavljuje proračun jeste da se euklidsko rastojanje do nepoznate lokacije težišta sa koordinatama $(\mathrm{X}, \mathrm{Y})$ aproksimira kva-

${ }^{3}$ Set covering problems.

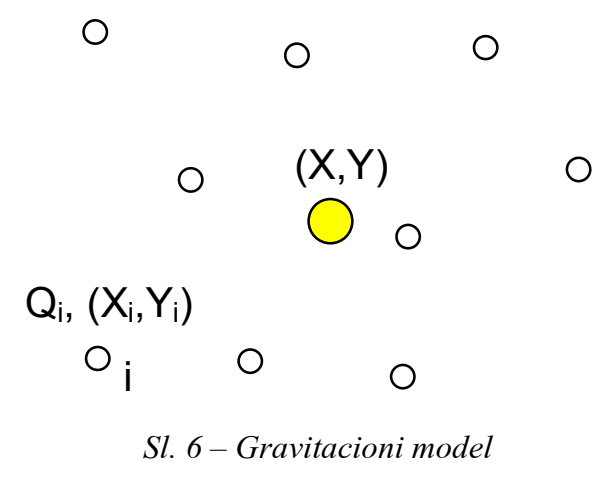

dratom tog rastojanja. Tada se težište određuje iz uslova da funkcija cilja dostigne minimum u tačkama $(\mathrm{X}, \mathrm{Y})$ :

$F(X, Y)=\sum_{i=1}^{n} Q_{i} \cdot\left[\left(X_{i}-X\right)^{2}+\left(Y_{i}-Y\right)^{2}\right]$

Može se pokazati da je, nakon diferenciranja prethodnog izraza po nepoznatim koordinatama, lokaciju objekta koji je potrebno pozicionirati moguće utvrditi na osnovu sledećeg izraza:

$X=\frac{\sum_{i=1}^{n} Q_{i} \cdot X_{i}}{\sum_{i=1}^{n} Q_{i}}, Y=\frac{\sum_{i=1}^{n} Q_{i} \cdot Y_{i}}{\sum_{i=1}^{n} Q_{i}}$

Ukoliko se koristi funkcija cilja sa euklidskim rastojanjem, a ne kvadratom tog rastojanja, tada izvodi na obe strane jednakosti sadrže i nepoznate koordinate $(\mathrm{X}, \mathrm{Y})$, pa se problem rešava iteracijom (tzv. Weiszfeldov metod).

Problem lociranja skladišta p-median

Jedna od najjednostavnijih, ali za logistiku veoma važnih formulacija loka- 
cijskog problema je Hakimijeva formulacija p-median problema:

razmotrimo skup od $\mathrm{n}$ korisnika prostorno disperzovanih u regionu. Problem je kako izabrati lokacije p identičnih skladišta koji opslužuje dati skup korisnika. Pretpostavlja se da postoji $m \geq p$ potencijalnih lokacija skladišta. Nakon što se svih p skladišta locira, svaki od n korisnika opsluživaće se iz njemu najbližeg skladišta;

sa jednom od najpoznatijih matematičkih formulacija ovog problema:

razmotrimo neorijentisani graf $\mathrm{G}=(\mathrm{N}, \mathrm{A})$ sa $\mathrm{m}$ čvorova. Neka $\mathrm{a}_{\mathrm{i}}$ označava broj zahteva za opslugom čvora i. Neka $d_{i j}$ označava rastojanje između čvorova i $\mathrm{i}$, a $\mathrm{p}$ broj objekata koje je potrebno locirati. Objekti mogu biti locirani u bilo kom od m čvorova.

Uvedimo $\mathrm{x}_{\mathrm{ij}}=\left\{\begin{array}{l}1, \mathrm{i} \text { se opslužuje preko } \mathrm{j} \\ 0, \mathrm{u} \text { suprotnom }\end{array}\right.$

Kako je cilj da se minimizira ukupni pređeni put, p-median problem formulisan je kao:

$$
\operatorname{MinF}=\sum_{i=1}^{m} \sum_{j=1}^{m} a_{i} d_{i j} x_{i j}
$$

pri ograničenjima:

$$
\begin{aligned}
& \sum_{j=1}^{m} x_{i j}=1, i=1,2, \ldots ., m \\
& \sum_{j=1}^{m} x_{j j}=p \\
& x_{j j} \geq x_{i j}, \quad i, j=1,2, \ldots . m ; \quad i j \\
& x_{i j} \in\{0,1\}, \quad i, j=1,2, \ldots . m ;
\end{aligned}
$$

\section{Generalizovani p-median problem}

Za razliku od Hakimijeve formulacije p-median problema, u uobičajenoj postavci lokacijsko-alokacijskog problema respektuju se i troškovi „otvaranja“ skladišta na lokaciji. Takođe, ograničenjima se definiše da li se korisnik snabdeva isključivo iz jednog skladišta ili se to čini sa više lokacija:

$$
\operatorname{Min} \rightarrow \sum_{j=1}^{m} F_{i} \cdot y_{i}+\sum_{i=1}^{m} \sum_{j=1}^{n} c_{i j} \cdot x_{i j}
$$

uz ograničenja:

$$
\begin{aligned}
& \sum_{j=1}^{m} x_{i j}=D_{j} \quad j=1,2, \ldots, n \\
& \sum_{j=1}^{n} x_{i j} \leq y_{i} \cdot \sum_{j=1}^{n} D_{j} \quad i=1,2, \ldots, m \\
& x_{i j} \geq 0 \quad i=1,2, \ldots, m \quad j=1,2, \ldots, n \\
& y_{i} \in\{0,1\} \quad i=1,2, \ldots, m
\end{aligned}
$$

gde je:

$\mathrm{m}$ - broj potencijalnih lokacija,

$\mathrm{n}$ - broj korisnika,

$\mathrm{c}_{\mathrm{ij}}$ - troškovi transporta jedne jedinice od skladišta i do korisnika j,

$F_{i}$ - fiksni troškovi otvaranja i rada skladišta i,

$D_{j}$ - broj jedinica koje zahteva korisnik $\mathrm{j}$, $\mathrm{x}_{\mathrm{ij}}$ - broj jedinica koje se isporučuju iz skladišta i do korisnika $j$,

$\mathrm{y}_{\mathrm{i}}-1$ ako je skladište $\mathrm{i}$ otvoreno, $0 \mathrm{u}$ suprotnom.

Formulisani problem predstavlja tzv. Miks celobrojni problem linearnog programiranja i često mu se oblik modifikuje i prilagođava primeni nekog od metoda za rešavanje LP problema. Tako 
se problem rešava primenom tehnike grananja i ograničavanja (branch and bound), zatim Lagranžeovom relaksacijom, Erlenkoterovom dual ascent procedurom, kao i primenom nekih heuristika.

\section{Problem pokrivanja skupa (set covering problem)}

Ovaj pristup uobičajen je za rešavanje problema u slučajevima kada je neophodno obezbediti da svaki korisnik bude „pokriven“ (covered), tj. opsluživan sa najmanje jedne lokacije. Rešavanje ovog tipa problema tipično je za slučaj lociranja vatrogasnih stanica, domova zdravlja, policijskih stanica, studentskih domova, skladišta maloprodajne mreže,... Ciljna funkcija minimizira troškove lociranja zahtevanog broja objekata.

$$
\text { Funkcija cilja: } \min \sum_{j=1}^{n} c_{j} x_{j}
$$

uz ograničenja: $\sum_{j=1}^{n} a_{i j} x_{j} \geq 1 \quad \mathrm{i}=1,2, \ldots, \mathrm{m}$

- svaki klijent treba da bude ,pokriven“ najmanje jednim objektom, gde su:

$x_{j} \in\{0,1\} \quad j=1,2, \ldots, n$ mestu j

$c_{j}-$ troškovi lociranja objekta na

$\mathrm{m}$ - broj korisnika,

$\mathrm{n}$ - broj objekata,

$$
\begin{aligned}
& \mathrm{a}_{\mathrm{ij}}\left\{\begin{array}{l}
1, \text { ako objekat na lokaciji j može pokriti klijenta i } \\
0, \mathrm{u} \text { svim ostalim slučajevima }
\end{array}\right. \\
& \mathrm{x}_{\mathrm{j}}\left\{\begin{array}{l}
1, \text { ako je objekat lociran na mestu } \mathrm{j} \\
0, \mathrm{u} \text { svim ostalim situacijama }
\end{array}\right.
\end{aligned}
$$

Problemi ovog tipa rešavaju se, najčešće, tehnikom grananja i ograničavanja (branch and bound), ali je za probleme većih dimenzija potrebno angažovati znatno računarsko vreme. Od heuristika je često $\mathrm{u}$ upotrebi greedy algorithm (,gramzivi“ algoritam).

\section{Specifični lokacijski problemi i vojne primene}

U zavisnosti od konkretnih zahteva koje generiše realizacija logističkih procesa problemi lociranja različitih resursa mogu zahtevati specifične pristupe. Kao ilustracija, prezentirane su neke od tih specifičnih primena teorije lokacije.

Problem lociranja depoa za prazne kontejnere kao lokacijski problem sa balansnim zahtevima

Posledica korišćenja povratnih logističkih jedinica jeste neophodnost aktiviranja kompleksnih procesa koji obuhvataju širok spektar različitih zadataka, od kojih posebno mesto zauzima izbor lokacija depoa za prazne kontejnere. Cilj je obezbeđenje dopreme praznih jedinica od korisnika i zadovoljenje tražnje za praznim kontejnerima - i jedno i drugo uz minimalne troškove. Specifičnost ovog problema jeste činjenica da tokovi kontejnera, u ovom slučaju postoje ne samo između korisnika i depoa već i između depoa radi realizacije balansnih zahteva koji su posledica neravnomernosti ponude i tražnje praznih kontejnera u gravitacionim zonama pojedinih depoa.

Ovaj problem, u slučaju determinističke tražnje, formulisali su Crainic, De- 
jax i Delorne (1989), kao „običan lokacijsko-alokacijski problem sa balansnim zahtevima i više artikala“. Autori preporučuju nekoliko formulacija ovog problema, a jedna od osnovnih ideja je problem minimalnog toka kroz mrežu.

M. Vidović, H. Hwangu, K. H. Kim (2003) uopštavaju ovaj zadatak i tretiraju ga kao lokacijski-ruting problem sa balansnim zahtevima, što podrazumeva primenu na sistemima za male kontejnere $\mathrm{i}$ palete. Pri tome se koristi modifikovana postavka problema Crainic, Dejax i Delorne (1989), kombinovana sa formulacijom lokacijskog-ruting problema Tuzua and Burke (1999), a rešenje je utvrđeno primenom genetskog algoritma.

\section{Odredivanje kapaciteta i lokacije vojnog centra za hitnu medicinsku pomoć}

Jedan od primera primene lokacijske teorije u optimizaciji prostornog rasporeda resursa medicinske zaštite u regionu, pod dejstvom hemijskih agensa ili fizičkog napada, razmatra R. S. Segall (2000). U radu se razmatra šest scenarija rasporeda vojnih stanica hitne medicinske pomoći, u slučaju kada su poznate raspodele zahteva za tom vrstom pomoći unutar određene teritorije.

\section{Lociranje novih objekata i raciona- lizacija postojećih kompleksa za smeštaj opasnih materija klase 1}

Kao rezultat rešavanja realnih problema lociranja objekata za smeštaj opasnih materija klase 1 (eksplozivne materije, prema klasifikaciji UN), radni tim Od- seka za logistiku Saobraćajnog fakulteta razvio je nekoliko lokacijskih modela koji su uspešno primenjivani na optimizaciji realnih problema. Posebno se mogu izdvojiti dve grupe modela. Model za definisanje optimalne strukture novih skladišnih objekata (S. Vukićević, M. Miljuš, 1994) i modeli za optimizaciju broja i rasporeda objekata u postojećim kompleksima (M. Vidović, S. Cvetić, 1996).

U prvom modelu za definisanu količinu materija koju je potrebno smestiti u kompleks, primenom modela LP definiše se raspored objekata uz respektovanje potrebnih bezbednosnih rastojanja, pri čemu funkcija cilja minimizira investicije u objekte, saobraćajnice i očekivanu štetu, koja se definiše preko verovatnoća uništenja pri različitim vrstama napada na objekte. U okviru rešavanja problema optimizacije postojeće strukture objekata razvijena su dva heuristička modela. Jedan koji se bavi optimizacijom strukture objekata namenjenih za smeštaj materija čije se prostorno dejstvo opisuje preko doleta, i drugi koji respektuje materije čije se dejstvo opisuje eksplozijom u masi, što podrazumeva prisustvo nelinearne funkcije koja determiniše potrebno minimalno rastojanje među objektima.

\section{Zaključak}

U radu su na sažet način predstavljene osnovne postavke lokacijske teorije koja danas, bez ikakve sumnje, predstavlja jednu od najrazvijenijih oblasti, kako operacionih istraživanja, tako i strateškog planiranja. Kompleksnost problema koji se tretiraju u okviru lokacijske analize i obimnost materije koja je evi- 
dentna već i po broju do sada publikovanih radova, govore da ovim radom nije mogao biti obuhvaćen čitav niz zadataka koji postoje u literaturi, ali i u realnim logističkim sistemima. Ipak, i ovakav prikaz lokacijske teorije dovoljan je razlog za samostalno istraživanje ove oblasti, pri čemu značajnu pomoć može pružiti navedena literatura.

Literatura:

[1] Aikens, C. H.: Facility location models for distribution planning, European Journal of Operational Research 22 (1985) 263-279.

[2] Daskin, M. S.: Network and Discrete Location: Models Algorithms and Applications, Wiley, New York, (1995).

[3] Francis, R. L.; McGinnis, L. F.; White, J. A: Locational analysis, European Journal of Operational Research 12 (1983) 220-252.

[4] Krarup, J.; Pruzan, P. M.: Selected families of location problems, Annals of Discrete Mathematics 5 (1979) 327-387.

[5] Leonardi, G.: A unifying framework for public facility location problems - Part 1: A critical overview and some unsolved problems, Environment and Planning A 13 (1981) 1001-1028.

[6] ReVelle, C.; Marks, D.; Liebman, J. C.: An analysis of private and public sector location models, Management Science 16 (11) (1970) 692-707.

[7] Tansel, B. C.; Francis, R. L.; Lowe, T. J.: Location on networks: A survey. Part I: The P-center and P-median problems, Management Science 29 (4) (1983 a) 482-497.

[8] Tansel, B. C.; Francis, R. L.; Lowe, T. J.: Location on networks: A survey. Part II: Exploiting tree network structure, Management Science 29 (4) (1983 b) 498-511.
[9] Weber, A.: Uber den Standort der Industrien, University of Chicago, (1929).

[10] Thünen J. H.: Der Isolierte Staat in Beziehung auf Landwirtschaft und Nationalökonomie, Berlin SchumacherZarchlin, (1875).

[11] Owen, S. H.; M. Daskin: Strategic facility location: A review, European Journal of Operational Research 111 (1998), 423-447.

[12] Dickman, B.: How the oldest recorded multiple facility location problem was solved, Location Science 3 (1), (1995), 55-60.

[13] Hakimi, S. L.: Optimum locations of switching centers and the absolute centers and medians of a graph, Operations Research 12, (1964) 450-459.

[14] Krarup, J., Pruzan, P. M.: The simple plant location problem: Survey and synthesis, European Journal of Operational Research 12, (1983), 36-81.

[15] Sanderesh, H.: Facility design, PWS Publishing Co., Boston (1997).

[16] Goetschalckh, M.: Logistic systems design, Avg. 1999, www.isye.gatech.edu.

[17] Crainic, T.; Dejax, P.; Delorme, L.: Models for multimode multicommodity location problems with interdepot balancing requirements, Annals of Operations Research, 18, (1989) 279-302.

[18] Vidović, M.; Hwang, H.; Kim K. H.: Locating depots for empty containers as a probabilistic location routing problem with balancing demand, Transport \& Logistics, No5, (2003) 71-87.

[19] Tuzun, D.; Burke, L.: A two-phase tabu search approach to the location routing problem, European Journal of Operational Research 116, (1999) 87-99.

[20] Segall, R. S.: Some quantitative methods for determining capacities and locations of military emergency medical facilities, Applied Mathematical Modelling 24 (2000) 365-389.

[21] Vidović, M.; Cvetić, S.: Optimizacija korišćenja postojećih kompleksa za skladištenje ubojnih sredstava, Vojnotehnički glasnik, god. XLIV, br 1, (1996), Beograd.

[22] Vukićević, S.; Miljuš M.: Predlog postupaka za optimizaciju strukture objekata novog skladišta za zadatu količinu UbS, Tematski skup Kvalitet uskladištenih UbS, (1994), Beograd. 